\title{
El reto de la educación: perspectivas sociales del profesor
}

\author{
Jorge Eliécer Pacheco-Gualdrón*
}

Magíster en Pedagogía, Licenciado en Español y Literatura. Profesor de la Facultad de Educación, Universidad Cooperativa de Colombia. Bucaramanga, Colombia.

Correo electrónico: jorge.pacheco@ucc. edu.co, jorpachecog@outlook.com

Recibido: 2 de junio del 2016

Aprobado: 23 de agosto del 2016

Cómo citar este artículo: Pacheco, Jorge. "El reto de la educación: perspectivas sociales del profesor". Rastros Rostros 18.33 (2016): xx-xx. Impreso. doi: http://dx.doi. org/10.16925/ra.v18i33.1847

\section{Resumen}

Propósito: este ensayo reflexiona sobre las finalidades de la educación en la actualidad, el rol del profesor y del estudiante y la importancia de la articulación entre la pedagogía y la sociedad. Temas: para ello, se consideran los conceptos de educación, sociedad, pedagogía, autoridad y liderazgo que deben estar presentes en el acto educativo. Desarrollo: A partir de algunos pasajes de la novela de Miguel de Unamuno: Amor y Pedagogía y tomando como referencia las ideas de Vigotski, Franco Serrano, Bazán, entre otros, se presentan algunas ideas sobre los retos de la educación actual. Conclusiones: esta reflexión sirve para definir los roles que asumen los profesores y los estudiantes en cuanto seres inmersos en una sociedad exigente que plantea nuevos retos.

Palabras clave: amor, educación, liderazgo, Miguel de Unamuno, sociedad. 


\title{
The challenge of education: social perspectives of the teacher
}

\begin{abstract}
Purpose: This essay reflects on the purposes of education today, on the role of teacher and student, and on the importance of the articulation between pedagogy and society. Themes: concepts of education, society, pedagogy, authority and leadership that must be present in the educational act are considered. Development: from some passages of Miguel de Unamuno's novel: Amor y Pedagogía (Love and Pedagogy) and using the ideas of Vigotski, Franco Serrano, Bazán, among others, as reference points, some ideas on the challenges of current education are presented. Conclusions: this reflection serves to define the roles assumed by teachers and students as beings immersed in a demanding society that poses new challenges.
\end{abstract}

Keywords: love, education, leadership, Miguel de Unamuno, society.

\section{O desafio da educação: perspectivas sociais do professor}

\section{Resumo}

Propósito: este ensaio reflete sobre as finalidades da educação na atualidade, o papel do professor e do estudante e a importância da articulação entre a pedagogia e a sociedade. Temas: para isso, são considerados os conceitos de educação, sociedade, pedagogia, autoridade e liderança que devem estar presentes no ato educativo. Desenvolvimento: a partir de algumas passagens da novela Amor y Pedagogía, de Miguel de Unamuno, e tomando como referência as ideias de Vigotski, Franco Serrano, Bazán, entre outros, apresentam-se algumas ideias sobre os desafios da educação atual. Conclusões: esta reflexão serve para definir os papéis que os professores e os estudantes assumem como seres imersos em uma sociedade exigente que apresenta novos desafios.

Palavras-chave: amor, educação, liderança, Miguel de Unamuno, sociedade. 
Tómese un niño cualquiera, digo, tómese desde su estado embrionario, aplíquesele la pedagogía sociológica y saldrá un genio. El genio se hace, diga el refrán lo que quiera; [...] y lo demostraré.

\section{Miguel de Unamuno. Amor y pedagogía}

Estas palabras, dichas por don Avito Carrascal, antes de salir a buscar a la futura madre de su hijo-genio, pone en evidencia el problema pedagógico al que este ensayo pretende aproximarse ¿Qué es educar? ¿Cuáles son sus finalidades? ¿Cuáles son sus estrategias? El personaje de Unamuno se empeña en crear un ser superior y genial a quien la sociedad tendrá que alabar por su capacidad intelectual. Para lograrlo, le reprime de toda clase de afectos y le impone el conocimiento científico. Riñe con su esposa cuando lo mima y no le tiene permitido leer poesía. Su experimento es un fracaso. El joven crece, pero de nada le sirve el saber enciclopédico que ha adquirido; queda incapacitado para la vida.

Se cree que la educación corresponde a inventar un hombre nuevo que incremente sus competencias, que mejore individualmente, sin tener en cuenta que el sujeto es educable por, y para ser parte de una sociedad, como dice Vigotski (22). Educar, desde este punto de vista, se refiere a lo que menciona Domingo Bazán: "Dotar de personalidad social a los actores, transmitir saberes y conocimientos considerados culturalmente legítimos, preparar para el mundo laboral, formar a los futuros líderes y ciudadanos, entre otras" (55).

El sujeto al ser educado se le otorgan las herramientas de orden instrumental y de valor, que le ayudan a vivir en sociedad. Estos conocimientos, como se ve, no son meramente prácticos sino que tienen que ver con el desempeño social que el estudiante hará de ellos. De nada sirve saber historia si no se reflexiona e interpretan los cambios culturales que subyacen de los momentos históricos. La matemática no cumple su labor si no se la relaciona con las otras áreas del conocimiento. Delors lo explicita diciendo: "Se puede, en mi opinión, afirmar que el futuro pertenecerá a los que mejor sepan crear, transmitir, absorber y aplicar los conocimientos". (45)

Este autor cita a la Comisión Internacional sobre Educación para el siglo XxI cuando nombra los cuatro pilares de la educación: enseñar a conocer, enseñar a hacer, enseñar a ser y enseñar a convivir. En estos cuatro preceptos se centra la tarea y el reto de la educación en la actualidad. Formar un ciudadano que quiera aprender y se sienta complacido al hacerlo, que aprenda algún oficio sobre un área específica que lo ayude a ser exitoso profesionalmente, que desarrolle sus atributos a través de la responsabilidad y del conocimiento de sí mismo y, por último, que sepa vivir en sociedad, que comprenda a los demás como seres distintos y a la vez complementarios.

El concepto de individualidad que malentiende don Carrascal al pensar que su hijo debe ser egoísta: "Sé ilógico a sus ojos, le dice, hasta que renunciando a clasificarte se digan: es él, Apolodoro Carrascal, especie única", tiene que ver con lo que plantea el M.E.N: "La subjetividad, en consecuencia, se abre a las dos dimensiones antes señaladas: la subjetividad individual o el autoconocimiento, y la autoestima personal y la subjetividad colectiva, como parte de un todo, desde los diferentes niveles de interacción social". (56-57)

Entonces, si la educación tiene como propósito esencial formar al ciudadano en todos los aspectos, es innegable que esta debe corresponder a las necesidades individuales y sociales que correspondan a la cultura en que está inmerso. El fin de educar debería ser: "Añadir una segunda naturaleza que concilie las necesidades y aspiraciones individuales con el bienestar de la sociedad". (Franco 152)

Esta responsabilidad social le permitirá al sujeto transformar su entorno. Bazán dice que "la escuela es vista como el lugar donde se hereda la sociedad y donde se construye una sociedad mejor" (60). Quiere decir que el saber instrumental no es suficiente y si ese fuera el objetivo de la educación, la tarea del educando consistiría en repetir fechas y datos históricos sin relación con el presente. La educación intenta perfeccionar intencionalmente las facultades humanas a favor de la comunidad.

Para llevar a cabo esta tarea, es necesaria una reflexión sobre el desarrollo del pensamiento crítico y creativo del estudiante. Pues, es mediante éste que el sujeto re-construirá la sociedad. Los alumnos, dice José Manuel Franco:

Tienen el deber no sólo de reproducirla [su cultura], sino de mejorarla. Eso dependerá, en parte, de la creatividad del maestro para generar espacios de aprendizaje que le permitan al joven [...] usar el entendimiento o la inteligencia sin la dirección o tutela de otro. (151) 
De esta manera, se ve cómo los fundamentos pedagógicos tratados encaminan a los conceptos de autonomía y solidaridad como lineamientos necesarios para que el alumno, por medio de la crítica y la creatividad, proponga un nuevo orden social más equitativo, justo y democrático. En esta característica se centra su responsabilidad social.

Sin embargo, surge la pregunta sobre el papel que desempeña el maestro en el desarrollo de la creatividad de sus alumnos. Don Carrascal impone sus decisiones a la fuerza, educa a su hijo a partir de un capricho y cree tener poder total sobre él. Su poder se basa en la autoridad de padre y científico. Su hijo es su conejillo de indias. Sin embargo, no es consecuente con lo que enseña. Le impide a su hijo enamorarse, pero él ama a su esposa. Le prohíbe la religión, pero él sigue algunas convicciones religiosas "por costumbre”. Esto hace que su hijo, en la madurez, le pierda el respeto e intente enfrentársele; cuando le dice que se ha enamorado el padre le contesta:

- ¿Y quién te ha mandado enamorarte?

- ¿Quién? El amor, o si quieres el determinismo psíquico, ese que me has enseñado.

El padre, tocado en lo vivo por este argumento, exclama:

- ¡El amor!, siempre el amor atravesándose en las grandes empresas... El amor es anti-pedagógico, anti-sociológico, anti-científico anti... todo. (152)

Esto lleva a reflexionar sobre cómo la imagen del maestro influye en la formación de sus alumnos. El docente no debería tener un perfil autoritario que se base únicamente en las relaciones de poder. Esta coerción no sería consecuente con la función educadora de la que se ha hablado anteriormente, puesto que, la opresión no generaría el pensamiento crítico y creativo, y mucho menos educaría en valores a la persona. Los Lineamientos Curriculares de la Educación Ética y Valores Humanos problematizan esta práctica diciendo que:

El autoritarismo, el trato irrespetuoso, las practicas pedagógicas pasivas, la ausencia de un espíritu investigativo y científico, continúan siendo preocupación de todos los que estamos deseosos de lograr para el país una educación a tono con el espíritu de la época. (M.E.N 61-62)

La solución es clara: el maestro debe imponerse sobre sus estudiantes de una forma más significativa y acorde con los objetivos que plantea la reflexión sobre el que-hacer pedagógico. A este respecto, José Manuel Franco, citando a Hinchey, dice:

Dos ideas claves para la enseñanza se han ido afianzando desde algún tiempo: la primera es que los maestros necesitan asumir su liderazgo si se quiere que los esfuerzos para mejorar la educación tengan éxito; la segunda es que los maestros deben asumir su liderazgo si la docencia aspira a ser aceptada como una profesión. (83-84)

La nueva idea de sociedad posmoderna exige una nueva manera de acercarse al alumno. La autoridad en el docente debilita, el liderazgo, por el contrario, fortalece los actos pedagógicos que se emprenden. Los docentes que reflexionan acerca de su liderazgo en la institución y en el aula con sus alumnos, además de ser creativos, inspiran, motivan, promueven el trabajo en equipo, etcétera. Todo esto desde la confianza y la credibilidad. La práctica pedagógica debería ejercerse desde el respeto y la credibilidad que el maestro les despierte a sus alumnos, y no desde la imposición tenaz de una calificación o una reprimenda.

Miguel de Unamuno se encargó de mostrarnos que don Avito Carrascal se equivocó al querer educar a su hijo sin objetivos sociales específicos, con una autoridad sin sentido, sin valores comunitarios e intentando separarlo de las emociones inherentes a la persona. Fracasa.

Hay que reflexionar la labor docente constantemente, nutrirse experiencias, equivocarse, estudiar, investigar para que no tengamos de escuchar la lamentable respuesta de Apolodoro, hijo de don Carrascal, cuando le dicen:

-Mira, Apolodoro, tú no estás bueno, tú tienes algo, algún mal interior de que ni tú mismo sospechas, y es menester que el médico te examine.

-Sí, ya te entiendo y sé lo que crees que tengo, pero es otra cosa; conozco mi enfermedad.

-Sí, el amor.

-No, la pedagogía. (154)

\section{Referencias}

Bazán, Domingo. El oficio del pedagogo. Argentina: Homo Sapiens Ediciones Rosario, 2008. Impreso.

Delors, Jacques. "Hacia la educación para todos a los largo de toda la vida”. Hacia dónde se dirigen los valores. Ed. 
Jérome Bindé. México: Fondo de Cultura Económica, 2010. Impreso.

Franco, José. "Habilidades de liderazgo de docentes de $11^{\circ}$ de un Colegio Privado de Bucaramanga, Colombia, medidas por el inventario de prácticas de liderazgo (LPI)". Temas III.2 (2008). Web. 7 de enero de 2017.

---. "El saber pedagógico del maestro como fundamento de la acción creativa y formativa en el aula de clase". Docencia universitaria II (2010). Web. 7 de enero de 2017.
M.E.N. Lineamientos curriculares. Educación ética y valores humanos. Bogotá: M.E.N, 1998. Impreso.

De Unamuno, Miguel. Amor y pedagogía. España: Vincens Vives, 2008. Impreso.

Vigotski, Lev. El desarrollo de los procesos psicológicos superiores. Barcelona: Editorial Crítica, 1996. 